\title{
PERBANDINGAN PERFORMANSI METODE JOHNSON DENGAN \\ HEURISTIK MULTI TUJUAN DITINJAU DARI MAKESPAN, TOTAL FLOW TIME DAN IDDLE TIME
}

\author{
Annisa Kesy Garside ${ }^{1}$
}

\begin{abstract}
This research tries to implement a method of machine scheduling for flow shop called Multi Objective Heuristic. To make easier application in attaining job sequence that machine must do along with makespan value, total flow time, and idle time, then a software is made. Next, we make a comparison of machine scheduling result performance between Multi Objective Heuristic Method and Johnson Method if viewed from makespan value, total flow time, and idle time. From the result of research concluded that heuristic with multi objectives method shows the solutions flow time total fewer than Johnson method.
\end{abstract}

Key Words: Performance, Makespan, Flow time.

\section{PENDAHULUAN}

Perkembangan industri khususnya industri manufaktur dewasa ini, telah memaksa kita untuk selalu mencari alternatif terbaik dalam usaha memenuhi kebutuhan yang beraneka ragam. Tetapi karena terbatasnya sumber daya perusahaan maka usaha tersebut menjadi sulit untuk dilakukan. Karena itu peningkatan utilitas dan produktivitas masing masing sumber daya harus segera dilakukan, khususnya sumber daya yang terlibat langsung di bidang produksi.

$$
\text { Penjadwalan produksi yang }
$$
tujuannya melakukan pengalokasian fasilitas produksi untuk melaksanakan suatu pekerjaan merupakan proses yang akan mempengaruhi tercapainya usaha peningkatan produktivitas dan utilitas sumber daya perusahaan khususnya dilantai produksi.

Sistem penjadwalan produksi yang saat ini paling banyak digunakan adalah dengan menggunakan Johnson's Rule dimana metode ini hanya menekankan minimasi makespan saja dalam mendapatkan sebuah jadwal produksi. Sedangkan metode penjadwalan yang baik harus mampu meningkatkan utilitas sumber daya melalui minimum flow time yang berarti waktu penyelesaian pekerjaan yang lebih cepat, waktu pengiriman barang sebelum due date yang telah ditetapkan, serta minimum Work In Process (WIP) dan iddle time (waktu tunggu) baik mesin maupun operator. Jika hasil penjadwalan dengan Johnson's Rule mampu meminimasi makespan ini berarti hanya membawa akibat turunnya production run. 
Penelitian ini akan mencoba untuk menganalisa dan mengaplikasikan sebuah metode penjadwalan heuristik yang mempertimbangkan beberapa kriteria yaitu minimum makespan, total flow time dan iddle time, sehingga diharapkan akan dapat diusulkan sebuah metode penjadwalan yang dapat menghasilkan jadwal produksi yang lebih baik ditinjau dari 3 kriteria yaitu makespan, total flow time dan iddle time.

\section{TINJAUAN PUSTAKA}

Penjadwalan produksi adalah pengalokasian sumber produksi selama periode tertentu untuk mengerjakan sejumlah tugas. Secara ideal tujuan dari proses penjadwalan yaitu :

1. Utilisasi sumber daya secara efisien

2. Kecepatan respon terhadap perubahan permintaan

3. Kecepatan melakukan penjadwalan dengan batas due date yang ditentukan

Kriteria performance yang dipakai dalam penilaian suatu hasil proses penjadwalan sering kali ditentukan berdasarkan kebijakan perusahaan. Kriteria yang biasa digunakan dalam penilaian terhadap hasil proses penjadwalan antara lain

1. Rata rata waktu alir atau rata rata waktu suatu pekerjaan berada dalam suatu sistem produksi ( mean flow time )

2. Waktu menganggur mesin

3. Rata rata lateness pekerjaan yaitu perbedaan antara waktu penyelesaian pekerjaan sesungguhnya dengan batas waktu penyelesaian pekerjaan tersebut,dll.

\section{Penjadwalan Flow Shop}

Suatu lantai produksi dikatakan mengikuti pola aliran tertentu disebut flow shop, jika memiliki ciri ciri sebagai berikut :

- Semua pekerjaan hanya diproses satu kali pada setiap mesin.

- Proses pengerjaan pada mesin A harus mendahului proses pengerjaan pada mesin B dan proses pengerjaan pada mesin B harus mendahului proses pengerjaan mesin $\mathrm{C}$.

Karakteristik flow shop terlihat dari aliran yang satu arah.

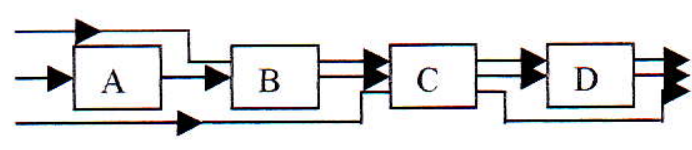

\section{Gambar 1. Pola Aliran Flow shop}

\section{Johnson Problem}

Masalah penjadwalan flow shop dengan 2 mesin dengan tujuan minimasi makespan dikenal dengan Johson problem. Dalam formulasinya job $\mathrm{j}$ diberikan waktu operasi $t_{j 1}$, memerlukan operasi pada mesin 1 dan $t_{j 2}$ memerlukan operasi pada mesin 2 setelah operasi pada mesin 1 selesai. Urutan optimal dapat dikarakterkan dengan aturan dibawah ini untuk job-job yang berpasangan.

\section{Teori 1}

Job i mendahului job j pada jadwal optimal jika

$$
\min \left\{t_{i 1}, t_{j 2}\right\} \leq \min \left\{t_{i 2}, t_{j 1}\right\}
$$




\section{Algoritma Johnson}

Langkah 1. Temukan minimum $\left\{t_{i 1}, t_{i 2}\right\}$

Langkah 2a. Jika minimum waktu proses memerlukan mesin 1, tempatkan job yang bersangkutan pada posisi pertama yang tersedia dalam urutan. Lanjutkan langkah 3.

Langkah $2 \mathrm{~b}$. Jika waktu proses memerlukan mesin 2, tempatkan job yang bersangkutan pada posisi terakhir yang tersedia. Lanjutkan ke langkah 3.

Langkah 3. Pindahkan job dari kumpulan job yang belum terjadwal dan kembali ke langkah 1.

\section{Perluasan Aturan Johnson}

Untuk masalah dengan kriteria makespan dan $m=3$ aturan johnson diatas masih layak untuk hanya mempertimbangkan jadwal permutasi saja untuk mencapai jadwal yang optimum, belum sulit untuk menggeneralisasikan aturan johnson menjadi aturan dominasi yaitu dengan aturan :

1. Jika $\min _{k}\left\{t_{k 1}\right\} \geq \max _{k}\left\{t_{k 2}\right\}$, maka job i mendahului job $\mathrm{j}$ dalam jadwal optimal jika :

$\min \left\{t_{i 1}+t_{i 2}+t_{i 3}\right\} \leq \min \left\{t_{i 2}+t_{i 3}, t_{j 1}+t_{j 2}\right\}$

2. Jika $\min _{k}\left\{t_{k 3}\right\} \geq \max _{k}\left\{t_{k 2}\right\}$, maka job i mendahului job $\mathrm{j}$ dalam jadwal optimal jika :

$\min \left\{t_{i 1}+t_{i 2}, t_{j 2}+t_{j 3}\right\} \leq \min \left\{t_{i 2}+t_{i 3}, t_{j 1}+t_{j 2}\right\}$
Metode Heuristik untuk Menjadwalkan Flow Shop dengan Multi Tujuan

Algoritma Heuristik untuk Minimum Flow Time, Makespan dan Iddle time adalah sebagai berikut :

Step 1: Selesaikan dengan "metode Campbell, Dudek, Smith yang meminimumkan makespan dan dapatkan satu jadwal.

Dapatkan satu jadwal dengan mengubah urutan job yaitu gantikan job yang berada pada urutan ke- $r$ dengan urutan $r+1$. Pilih jadwal yang menghasilkan makespan minimum. Lanjutkan proses tersebut dengan job yang berpasangan, dimana $V r, i \leq r \leq n-1$ dan pilih jadwal yang menghasilkan makespan yang lebih kecil. Jadual ini menjadi daftar jadwal ' $\mathrm{S}$ ' dengan makespan dan total flow time ' $F$ '.

Step 2 : Hitung nilai nilai berikut untuk job yang berada pada posisi ke- $r$ dalam jadual $\mathrm{S}$, dimana $1 \leq r \leq n-1$

$$
D_{[r]}=\sum_{j=1}^{m} t_{[r], j}-\sum_{j=1}^{m} t_{[r+1], j}
$$

$D_{[r]}=\sum_{j=1}^{m}\left\{(m-j+1) t_{[r\}, j}\right\}-\sum_{j=1}^{m}\left\{(m-j+1) t_{[r+1], j}\right\}$

Step 3 : Buat daftar job yang nilai $D_{[r]} \geq 0$

Step 4 : Jika jadwal ( list ) kosong, lanjutkan ke step 10 , selain itu lanjutkan ke step 5

Step 5 : List job disusun dengan urutan menurun menurut nilai $D_{[r]}$ yang tertinggi disusun terlebih dahulu. Jika terjadi kesamaan nilai $D_{[r]}$, maka ranking disusun dengan mempertimbangkan nilai $D_{[r]}^{\prime}$ yang tinggi. 
Step 6: Sebut job yang berada pada urutan pertama sebagai job Q saling tukarkan posisi job yang berada pada urutan $Q$ dan job yang berada pada posisi $Q+1$ dalam jadual S. sebut jadwal yang dihasilkan sebagai $S^{\prime}$.

Hitung makespan (M'), total flow time (F') dan total idle time (I'). Dari sini dapat dilihat bahwa semakin besar kesempatan mengurangi flow time ketike job yang bersangkutan digantikan oleh job yang sesuai.

Step 7 : Hitung penambahan relatif makespan, flow time dan idle time dari $S^{\prime}$ dengan $\mathrm{S}$.

$R S^{\prime}=\frac{M^{\prime}-\min \left(M^{\prime}, M\right)}{\min \left(M^{\prime}, M\right)}+\frac{F^{\prime}-\min \left(F^{\prime}, F\right)}{\min \left(F^{\prime}, F\right)}+\frac{I^{\prime}-\min \left(I^{\prime}-I\right)}{\min \left(I^{\prime}, I\right)}$

dan

$R S=\frac{M-\min \left(M^{\prime}, M\right)}{\min \left(M^{\prime}, M\right)}+\frac{F-\min \left(F^{\prime}, F\right)}{\min \left(F^{\prime}, F\right)}+\frac{I-\min \left(I^{\prime}, I\right)}{\min \left(I^{\prime}, I\right)}$

Step 8: Jika $R S^{\prime}<R S$, kemudian generate $\mathrm{S}^{\prime}$, menjadi daftar baru sebagai $\mathrm{S}$. (dimana semua parameter $\mathrm{S}=\mathrm{S}^{\prime} ; \mathrm{M}=\mathrm{M}^{\prime}$; $\mathrm{F}=\mathrm{F}^{\prime} ; \mathrm{I}=\mathrm{I}^{\prime}$ ) dan kembali ke step 2. Selain itu ke step 9.

Step 9 : Hilangkan job Q dari kumpulan job yang belum terjadwalkan. Jika urutan yang terbentuk belum urutan yang terakhir, kembali step 6. Jika urutan yang terbentuk merupakan urutan terakhir lanjutkan step 10 .

Step 10 : Daftar tersebut dengan makespan, total flow time dan idle time mesin mesinnya menjadi solusi. Stop.

\section{METODOLOGI PENELITIAN}

Data yang diperlukan adalah :

1. Jenis dan banyaknya produk (job) yang akan dijadwalkan.

2. Urutan proses produksi dari masingmasing produk/jenis mesin yang dibutuhkan untuk membuat masingmasing produk.

3. Jumlah Demand/permintaan untuk masing-masing produk.

4. Kapasitas dari tiap mesin.

5. Waktu pengerjaan produk pada tiap mesin. Untuk proses yang sifatnya tidak otomatis maka sebaiknya waktu yang digunakan adalah waktu standard (waktu pengerjaan sebuah produk yang mempertimbangkan performance rating dan allowance-allowance yang diperlukan untuk menyelesaikan pekerjaan) dan bukan berupa data waktu pengamatan mentah.

Dari data tersebut, kemudian dibuat dalam bentuk sebuah matriks waktu pengerjaan job/produk pada masing-masing mesin. Hal yang perlu dipertimbangkan dalam membuat matriks tersebut jika ternyata tiap produk memiliki jumlah demand dan kapasitas mesin yang berbeda maka harus diolah agar tiap job memiliki satuan waktu yang sama pada tiap mesin.

\section{Pembuatan Program Penjadwalan Heuristik Multi Tujuan.}

Untuk mendapatkan jadwal produksi dan perhitungan makespan dengan metode 
heuristik multi tujuan akan membutuhkan waktu yang lama karena step-step perhitungannya sangat panjang sehingga dibuat sebuah program penjadwalan heuristik multi tujuan untuk mempermudah proses perhitungan.

Pada gambar 2 ditunjukkan tampilan entry data matriks mesin/job melalui program penjadwalan heuristik. Program tersebut dibuat dengan menggunakan Visual Basic 5.0. Pada gambar 3 dapat dilihat tampilan hasil pemrosesan dengan menggunakan metode heuristik.

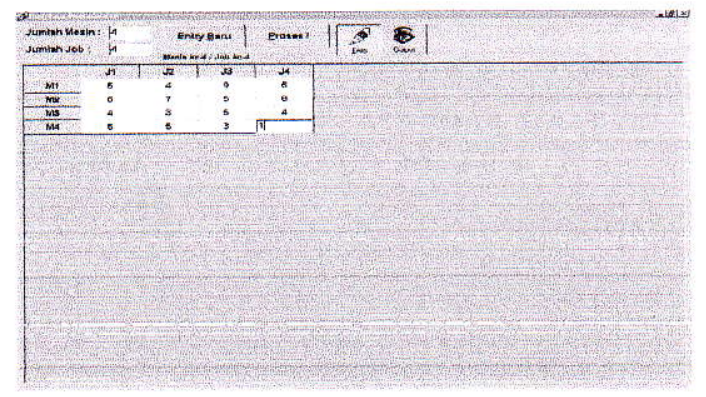

Gambar 2

Tampilan input program penjadwalan metode heuristik.

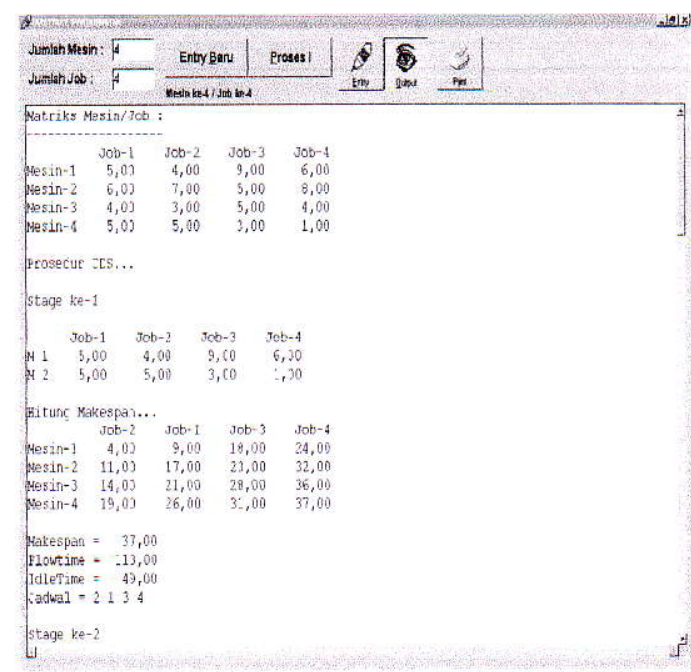

Gambar 3

Tampilan output program penjadwalan metode heuristik
Pengumpulan Data Matriks waktu

\section{Pengerjaan Job pada Mesin}

Untuk melihat performansi dari kedua metode maka dikumpulkan beberapa data matriks waktu pengerjaan job pada mesin yang memiliki karakteristik jumlah job dan jumlah mesin yang berbeda-beda. Dan selanjutnya data yang didapat diolah dengan menggunakan kedua metode dan kemudian dianalisa hasilnya ditinjau dari segi makespan, total flow time dan iddle time.

Data matriks waktu pengerjaan job (dalam satuan menit) pada mesin yang akan ditentukan jadwal urutan prosesnya adalah :

\section{Problem 1}

\begin{tabular}{|c|c|c|c|c|c|c|c|c|}
\hline Job & $\mathbf{1}$ & $\mathbf{2}$ & $\mathbf{3}$ & $\mathbf{4}$ & $\mathbf{5}$ & $\mathbf{6}$ & $\mathbf{7}$ & $\mathbf{8}$ \\
\hline Mesin 1 & 10 & 12 & 13 & 7 & 8 & 5 & 4 & 3 \\
\hline Mesin 2 & 4 & 9 & 11 & 8 & 7 & 5 & 10 & 2 \\
\hline
\end{tabular}

2. Problem 2

\begin{tabular}{|l|l|l|l|l|l|l|l|l|l|l|}
\hline Job & $\mathbf{1}$ & $\mathbf{2}$ & $\mathbf{3}$ & $\mathbf{4}$ & $\mathbf{5}$ & $\mathbf{6}$ & $\mathbf{7}$ & $\mathbf{8}$ & $\mathbf{9}$ & $\mathbf{1 0}$ \\
\hline Mesin 1 & 8 & 7 & 9 & 7 & 2 & 5 & 5 & 2 & 7 & 1 \\
\hline Mesin 2 & 6 & 5 & 2 & 8 & 4 & 1 & 7 & 3 & 3 & 5 \\
\hline
\end{tabular}

2. Problem 3

\begin{tabular}{|c|c|c|c|}
\hline Job & $\mathbf{1}$ & $\mathbf{2}$ & $\mathbf{3}$ \\
\hline Mesin 1 & 7 & 10 & 8 \\
\hline Mesin 2 & 5 & 7 & 9 \\
\hline Mesin 3 & 11 & 5 & 9 \\
\hline Mesin 4 & 8 & 9 & 8 \\
\hline
\end{tabular}

3. Problem 4

\begin{tabular}{|c|c|c|c|}
\hline Job & $\mathbf{1}$ & $\mathbf{2}$ & $\mathbf{3}$ \\
\hline Mesin 1 & 10 & 8 & 7 \\
\hline Mesin 2 & 12 & 5 & 9 \\
\hline Mesin 3 & 15 & 7 & 12 \\
\hline Mesin 4 & 9 & 1 & 10 \\
\hline Mesin 5 & 11 & 3 & 9 \\
\hline Mesin 6 & 13 & 6 & 5 \\
\hline
\end{tabular}


4. Problem 5

\begin{tabular}{|c|c|c|c|c|}
\hline Job & 1 & 2 & 3 & 4 \\
\hline Mesin 1 & 5 & 6 & 4 & 5 \\
\hline Mesin 2 & 4 & 7 & 3 & 5 \\
\hline Mesin 3 & 9 & 5 & 5 & 3 \\
\hline Mesin 4 & 6 & 8 & 4 & 1 \\
\hline
\end{tabular}

\section{Problem 6}

\begin{tabular}{|c|c|c|c|c|c|}
\hline Job & 1 & 2 & 3 & 4 & 5 \\
\hline Mesin 1 & 5 & 7 & 8 & 6 & 9 \\
\hline Mesin 2 & 10 & 12 & 5 & 4 & 9 \\
\hline Mesin 3 & 11 & 11 & 7 & 3 & 8 \\
\hline Mesin 4 & 21 & 9 & 19 & 4 & 1 \\
\hline
\end{tabular}

\section{Problem 7}

\begin{tabular}{|c|c|c|c|c|c|c|c|c|}
\hline Job & 1 & 2 & 3 & 4 & 5 & 6 & 7 & 8 \\
\hline Mesin 1 & 12 & 9 & 8 & 6 & 4 & 7 & 6 & 8 \\
\hline Mesin 2 & 3 & 5 & 6 & 4 & 7 & 8 & 5 & 2 \\
\hline Mesin 3 & 9 & 8 & 4 & 7 & 3 & 10 & 4 & 6 \\
\hline Mesin 4 & 5 & 8 & 2 & 9 & 6 & 4 & 7 & 8 \\
\hline Mesin 5 & 6 & 7 & 4 & 5 & 9 & 8 & 7 & 4 \\
\hline Mesin 6 & 3 & 8 & 9 & 7 & 2 & 1 & 4 & 4 \\
\hline Mesin 7 & 8 & 2 & 5 & 7 & 3 & 8 & 9 & 6 \\
\hline
\end{tabular}

\section{Problem 8}

\begin{tabular}{|c|c|c|c|c|c|}
\hline Job & 1 & 2 & 3 & 4 & 5 \\
\hline Mesin 1 & 4 & 7 & 9 & 10 & 8 \\
\hline Mesin 2 & 3 & 6 & 5 & 9 & 4 \\
\hline Mesin 3 & 10 & 9 & 8 & 7 & 4 \\
\hline Mesin 4 & 7 & 6 & 4 & 9 & 7 \\
\hline
\end{tabular}

9. Problem 9

\begin{tabular}{|c|c|c|c|c|c|c|c|}
\hline Job & $\mathbf{1}$ & $\mathbf{2}$ & $\mathbf{3}$ & $\mathbf{4}$ & $\mathbf{5}$ & $\mathbf{6}$ & $\mathbf{7}$ \\
\hline Mesin 1 & 4,58 & 1,27 & 2,55 & 3,26 & 4,50 & 2,87 & 1,50 \\
\hline Mesin 2 & 1,32 & 0,50 & 0,64 & 0,87 & 0,85 & 0,75 & 0,50 \\
\hline Mesin 3 & 1,06 & 0,51 & 0,62 & 0,58 & 0,70 & 0,47 & 0,58 \\
\hline Mesin 4 & 1,52 & 0,81 & 1,19 & 1,25 & 0,99 & 0,75 & 0,72 \\
\hline
\end{tabular}

\section{HASIL DAN PEMBAHASAN}

Dari data/problem diatas, maka langkah pertama adalah membuat jadwal produksi dengan menggunakan metode Johnson. Untuk mempermudah dalam pembuatan jadwal dan perhitungan makespan, flow time maka digunakan bantuan software Quantitative System (QS).

$$
\text { Dari running QS dengan }
$$
memasukkan input berupa matriks pengerjaan job ke mesin dan memilih metode Johnson, diperoleh solusi machine schedule/urutan pengerjaan job untuk tiap problem penjadwalan yang ada beserta beberapa parameter kriterianya. Solusi Jadwal untuk keseluruhan problem dengan metode johnson dapat dilihat pada tabel berikut : 
Tabel 1

Hasil Penjadwalan Dengan Metode Johnson (dalam Satuan menit)

\begin{tabular}{|c|c|c|c|c|c|c|}
\hline Problem & Karakteristik & $\begin{array}{c}\text { Urutan } \\
\text { Jadwal }\end{array}$ & $\begin{array}{c}\text { Make- } \\
\text { span }\end{array}$ & MC & $\begin{array}{c}\text { Total Flow } \\
\text { Time }\end{array}$ & $\begin{array}{c}\text { Iddle } \\
\text { Time }\end{array}$ \\
\hline 1 & 2 mesin, 7 job & 76432518 & 65 & 41,87 & $41,87 \times 7=335$ & 9 \\
\hline 2 & 2 mesin, 10 job & 10857412936 & 54 & 29,5 & $29,5 \times 10=295$ & 9 \\
\hline 3 & 3 mesin, 4 job & 2143 & 48 & 34,5 & 138 & 19 \\
\hline 4 & 3 mesin, 6 job & 432516 & 81 & 53,83 & 329 & 75 \\
\hline 5 & 4 mesin, 4 job & 2134 & 37 & 28,25 & 113 & 49 \\
\hline 6 & 5 mesin, 4 job & 1234 & 80 & 54 & 216 & 168 \\
\hline 7 & 7 mesin, 8 job & 47618352 & 98 & 71,5 & 572 & 215 \\
\hline 8 & 4 mesin, 5 job & 14523 & 56 & 43,4 & 217 & 53 \\
\hline 9 & 4 mesin, 7 job & 1435267 & 22,33 & 15,83 & 110,86 & 47,8 \\
\hline
\end{tabular}

Selanjutnya untuk mendapatkan solusi penjadwalan dengan metode heuristik multi tujuan dilakukan running dengan memasukkan data pada program yang telah dibuat sebelumnya. Hasil penjadwalan dengan menggunakan metode heuristik multi tujuan dapat diringkas sebagai berikut

Tabel 2

\section{Hasil Penjadwalan Dengan Metode Heuristik (dalam satuan menit)}

\begin{tabular}{|c|c|c|c|c|c|}
\hline Problem & Karakteristik & $\begin{array}{c}\text { Urutan } \\
\text { Jadwal }\end{array}$ & $\begin{array}{c}\text { Make- } \\
\text { span }\end{array}$ & $\begin{array}{c}\text { Total Flow } \\
\text { Time }\end{array}$ & $\begin{array}{c}\text { Iddle } \\
\text { Time }\end{array}$ \\
\hline 1 & 2 mesin, 7 job & 67543218 & 65 & 326 & 9 \\
\hline 2 & 2 mesin, 10 job & 10852741936 & 54 & 289 & 10 \\
\hline 3 & 3 mesin, 4 job & 2143 & 48 & 138 & 19 \\
\hline 4 & 3 mesin, 6 job & 412536 & 81 & 310 & 75 \\
\hline 5 & 4 mesin, 4 job & 2143 & 38 & 113 & 47 \\
\hline 6 & 5 mesin, 4 job & 1234 & 80 & 216 & 168 \\
\hline 7 & 7 mesin, 8 job & 74261358 & 93 & 560 & 198 \\
\hline 8 & 4 mesin, 5 job & 12435 & 57 & 209 & 50 \\
\hline 9 & 4 mesin, 7 job & 2364157 & 22,33 & 93 & 47,79 \\
\hline
\end{tabular}

Dari Hasil penjadwalan dan perhitungan makespan, total flow time dan iddle time dengan metode Johnson dan
Heuristik Multi Tujuan maka tahap selanjutnya dilakukan perbandingan performansi dari kedua metode tersebut. 
Tabel 3

Perbandingan Hasil Penjadwalan Metode Johnson dan Heuristik Multi Tujuan

\begin{tabular}{|c|c|c|c|c|c|}
\hline Problem & Karakteristik & Metode & $\begin{array}{c}\text { Makespan } \\
\text { (menit) }\end{array}$ & $\begin{array}{c}\text { Total } \\
\text { Flow Time } \\
\text { (menit) }\end{array}$ & $\begin{array}{l}\text { Iddle Time } \\
\text { (menit) }\end{array}$ \\
\hline \multirow[t]{2}{*}{1} & \multirow[t]{2}{*}{2 mesin, 7 job } & - Heuristik & 65 & 326 & 9 \\
\hline & & - Johnson & 65 & 335 & 9 \\
\hline \multirow[t]{2}{*}{2} & \multirow[t]{2}{*}{2 mesin, 10 job } & - Heuristik & 54 & 289 & 10 \\
\hline & & - Johnson & 54 & 295 & 9 \\
\hline \multirow[t]{2}{*}{3} & \multirow[t]{2}{*}{3 mesin, 4 job } & - Heuristik & 48 & 138 & 19 \\
\hline & & - Johnson & 48 & 138 & 19 \\
\hline \multirow[t]{2}{*}{4} & \multirow[t]{2}{*}{3 mesin, 6 job } & - Heuristik & 81 & 310 & 75 \\
\hline & & - Johnson & 81 & 329 & 75 \\
\hline \multirow[t]{2}{*}{5} & \multirow[t]{2}{*}{4 mesin, 4 job } & - Heuristik & 38 & 113 & 47 \\
\hline & & - johmson & 37 & 113 & 49 \\
\hline \multirow[t]{2}{*}{6} & \multirow[t]{2}{*}{5 mesin, 4 job } & - Heuristik & 80 & 216 & 168 \\
\hline & & - Johnson & 80 & 216 & 168 \\
\hline \multirow[t]{2}{*}{7} & \multirow[t]{2}{*}{7 mesin, 8 job } & - Heuristik & 93 & 560 & 198 \\
\hline & & - Johnson & 98 & 572 & 215 \\
\hline \multirow[t]{2}{*}{8} & \multirow[t]{2}{*}{4 mesin, 5 job } & - Heuristik & 57 & 209 & 50 \\
\hline & & - Johnson & 56 & 217 & 53 \\
\hline \multirow[t]{2}{*}{9} & \multirow[t]{2}{*}{4 mesin, 7 job } & - Heuristik & 22,33 & 93 & 47,79 \\
\hline & & - Johnson & 22,33 & 110,86 & 47,79 \\
\hline
\end{tabular}

Karena pada dasarnya kriteria untuk menilai jadwal urutan proses yang terbaik didasarkan pada minimasi makespan, total flow time dan iddle time maka dari tabel 3 tersebut dapat dilihat bahwa metode heuristik secara umum mampu menghasilkan solusi jadwal yang lebih baik ditinjau dari ketiga kriteria yang ada. Perbaikan hasil dengan metode heuristik tersebut terutama dalam kriteria total flow time yang lebih kecil/minimal dibanding dengan metode Johnson.

Keefektifan perbaikan hasil dengan menggunakan metode heuristik semakin baik apabila jumlah mesin dan job yang ada semakin banyak (sebagai contoh dalam problem 7 dan 9). Selanjutnya dapat dilihat dengan semakin banyaknya job (contoh pada problem 1, 2, 4, 7 dan 9) hasil solusi jadwal yang dihasilkan cukup berbeda secara signifikan dengan metode Johnson terutama dalam minimasi total flow timenya. Dari sini dapat ditarik kesimpulan bahwa dengan semakin banyaknya job maka metode heuristik mampu menghasilkan solusi jadwal yang lebih optimal dibanding dengan metode Johnson. Hal ini disebabkan dengan semakin banyaknya job maka akan semakin besar kesempatan untuk melakukan permutasi/pertukaran antar job dalam proses heuristik multi tujuan sehingga memungkinkan diperolehnya jadwal baru yang lebih minimal ditinjau dari segi makespan, total flow time dan iddle time Namun disisi lain dapat dilihat untuk problem 3, 5 dan 6 yang memiliki 
karakteristik penjadwalan untuk 4 job walaupun dengan jumlah mesin yang berbeda ternyata tidak ada perbedaan hasil yang cukup signifikan dengan metode Johnson (bahkan untuk problem 3 dan 6 , hasil yang diperoleh sama dengan metode Johnson). Hal ini mungkin disebabkan karena dengan 4 job yang ada maka jumlah pertukaran/permutasi yang ada cukup sedikit sehingga kemungkinan untuk mendapatkan solusi jadwal baru yang lebih baik kemungkinannya adalah kecil.

Dari keseluruhan solusi jadwal, dapat dilihat bahwa dengan metode heuristik ternyata nilai makespan yang dihasilkan tidak jauh berbeda dengan metode Johnson.

Sehingga dapat ditarik kesimpulan bahwa metode johnson memang terbukti dapat menghasilkan solusi jadwal yang mempunya nilai minimal ditinjau dari segi makespannya. Sedangkan dalam metode heuristik multi tujuan untuk menjamin agar diperoleh jadwal yang makespannya minimal digunakan metode CDS yang pada dasarnya merupakan perluasan dari metode Johnson.

Dari analisa diatas dapat ditarik kesimpulan bahwa untuk problem penjadwalan yang melibatkan jumlah job semakin banyak ( Job lebih dari 4 ) maka sebaiknya digunakan metode Heuristik Multi Tujuan, karena telah terbukti mampu menghasilkan solusi jadwal yang lebih baik dibanding dengan metode Johnson ditinjau dari tiga kriteria yaitu makespan, total flow time dan iddle time. Sedangkan untuk problem penjadwalan yang melibatkan sedikit job ( job kurang dari sama dengan 4 ) maka dapat digunakan metode Johnson yang sudah ada karena terbukti mampu menghasilkan solusi yang baik dan proses perhitungannya yang cukup mudah dan cepat. Namun secara keseluruhan, dapat dikatakan bahwa metode heuristik multi tujuan ini dapat diterapkan untuk semua problem penjadwalan dengan karakteristik jumlah job dan mesin yang bervariasi dan mampu menghasilkan solusi yang lebih baik dibanding dengan metode Johnson. Sedangkan kelemahan yang ada pada metode heuristik multi tujuan ini adalah iterasi yang cukup panjang dan membutuhkan waktu yang lebih lama dibanding dengan metode Johnson dapat diselesaikan dengan membuat program penjadwalah heuristik multi tujuan.

\section{KESIMPULAN}

Metode Heuristik Multi Tujuan secara umum mampu menghasilkan solusi jadwal yang lebih baik ditinjau dari ketiga kriteria yang ada. Perbaikan hasil dengan metode heuristik tersebut terutama dalam kriteria total flow time yang lebih $\mathrm{kecil} /$ minimal dibanding dengan metode Johnson.

Keefektifan perbaikan hasil dengan menggunakan metode heuristik semakin baik apabila jumlah mesin dan job yang ada semakin banyak. Dari analisa dapat ditarik kesimpulan bahwa untuk problem penjadwalan yang melibatkan jumlah job semakin banyak ( Job lebih dari 4 ) dengan 
jumlah mesin tertentu maka sebaiknya digunakan metode Heuristik Multi Tujuan. Sedangkan untuk problem penjadwalan yang melibatkan sedikit job ( job kurang dari sama dengan 4 ) maka dapat digunakan metode Johnson yang sudah ada karena terbukti mampu menghasilkan solusi yang baik dan proses perhitungannya yang cukup mudah dan cepat.

\section{DAFTAR PUSTAKA}

Baker, Kenneth R.,1976, "Introduction To

Sequencing and Schedulling", John

Wiley and Son.

Elsayed A., Thomas O. boucher, "Analysis

And Control Of Production System",

Prentice Hall International.

Morton, Thomas E.,1993, "Heuristik

Schedulling System".

Rajendran, Chandra S., 1995, “Heuristik For

Scheduling In Flow Shop With Multi

Objectives", Europen Journal Of operation research, Volume 82.

Walpole, Ronald and Raymond $\mathrm{H}$.

Myers,1986, "Ilmu Peluang dan

statistik untuk Insiyur dan Ilmuwan",

ITB Bandung.

Wignjosoebroto, Sritomo.,1992, “Teknik

Tata Cara dan Pengukuran Kerja”,

Guna Widya. 